\title{
New records of Chironomidae (Diptera) of Tuvalu
}

\author{
Ryuhei Ueno*, Kiyoshi Satake and Hiroya Yamano \\ National Institute for Environmental Studies, 16-2, Onogawa, Tsukuba, Ibaraki 305-8506, Japan
}

Received 11 March 2014; Accepted 16 December 2014

\begin{abstract}
Here we report the chironomid fauna of Tuvalu for the first time. Four species belonging to two subfamilies were collected on Fongafale Island. At least one species inhabited a freshwater environment. We describe male imagines of Compterosmittia longipalpis sp. n., Pseudosmittia tuvaluensis sp. n. and Pseudosmittia amplexivirga sp. n. We also describe the morphology of Chironomus sp. larvae inhabiting a wet taro swamp.
\end{abstract}

Key words: Chironomidae / Diptera / Funafuti Atoll / new species / Tuvalu

\section{Introduction}

To date the chironomid faunae of the Pacific islands have been studied in detail in the Samoan Islands (Edwards, 1928), Marquesas Islands (Edwards, 1933), Hawaiian Islands (Hardy, 1960) and in a broad sense in Micronesia (Tokunaga, 1964), but not yet in the state of Tuvalu. Laird (1956) reported the absence of Chironomidae from aquatic habitats on Funafuti Atoll, Tuvalu. Low-profile Pacific islands such as those of Tuvalu could suffer from inundation caused by rising sea levels. Further, Tuvalu is currently suffering from the effects of inappropriate land development (Yamano et al., 2007). There is therefore an urgent need to study the florae and faunae of Pacific low-profile islands. In 2009, the second and third authors of this study visited Fongafale Island in Tuvalu and collected chironomid specimens. Here we report the morphology and cytochrome $c$ oxidase I (COI) DNA sequences of the Tuvaluan chironomids for the first time.

\section{Methods and terminology}

The general terminology and abbreviations follows Sæther (1980). The definition of VR2 (venarum ratio 2) of Pseudosmittia follows Sæther (2004). Length ratio of palpomeres $5 / 3$ follows Lin et al. (2013). All materials were collected by the second author. Adults were collected with a sweep net. Larvae were collected with a D-frame net. Collections were attempted at four sites on Fongafale, the most densely populated island in Tuvalu (Fig. 1). Site 1 is located in a wetland near a transmission tower. Site 2 is a stand of bushes on the west coast, the side facing a lagoon

\footnotetext{
*Corresponding author: uenor@nies.go.jp
}

of the atoll. Site 3 is a mangrove forest on a ridge between a small brackish lake and the ocean. Site 4 is located in a taro (Colocasia esculenta) swamp under cultivation near an airstrip. The adults and larvae were preserved in $80 \%$ or $99.5 \%$ ethanol, respectively. Microscope slides were prepared with Canada balsam using the usual methods (Pinder, 1989). Measurements are given as ranges followed by a mean (when 3 or more measurements were taken), followed by the number measured $(n)$ in parenthesis. All specimens studied here, including the types of the new species, have been deposited in the National Institute for Environmental Studies, Tsukuba, Japan.

The specimens of Compterosmittia longipalpis, Pseudosmittia tuvaluensis and Chironomus sp. were subjected to DNA extraction for direct sequencing of a mitochondrial gene encoding COI, described by Kondo et al. (submitted), although PCR products were not recovered from C. longipalpis samples. The only sample of Pseudosmittia amplexivirga had been prepared for a slide, before the DNA analysis was planned. The length of the obtained sequence was $658 \mathrm{bp}$, excluding the primer region. Nucleotide sequence data are available in the DDBJ/EMBL/GenBank databases under the accession numbers AB769378AB769382. After DNA extraction, the recovered translucent specimens were preserved in $99.5 \%$ ethanol and used for additional morphological observations.

\section{Subfamily Orthocladiinae}

\section{Compterosmittia longipalpis sp. n. (Fig. 2)}

Type material: Holotype male, TUVALU: Funafuti Atoll, Fongafale Island, a wetland near the transmission 

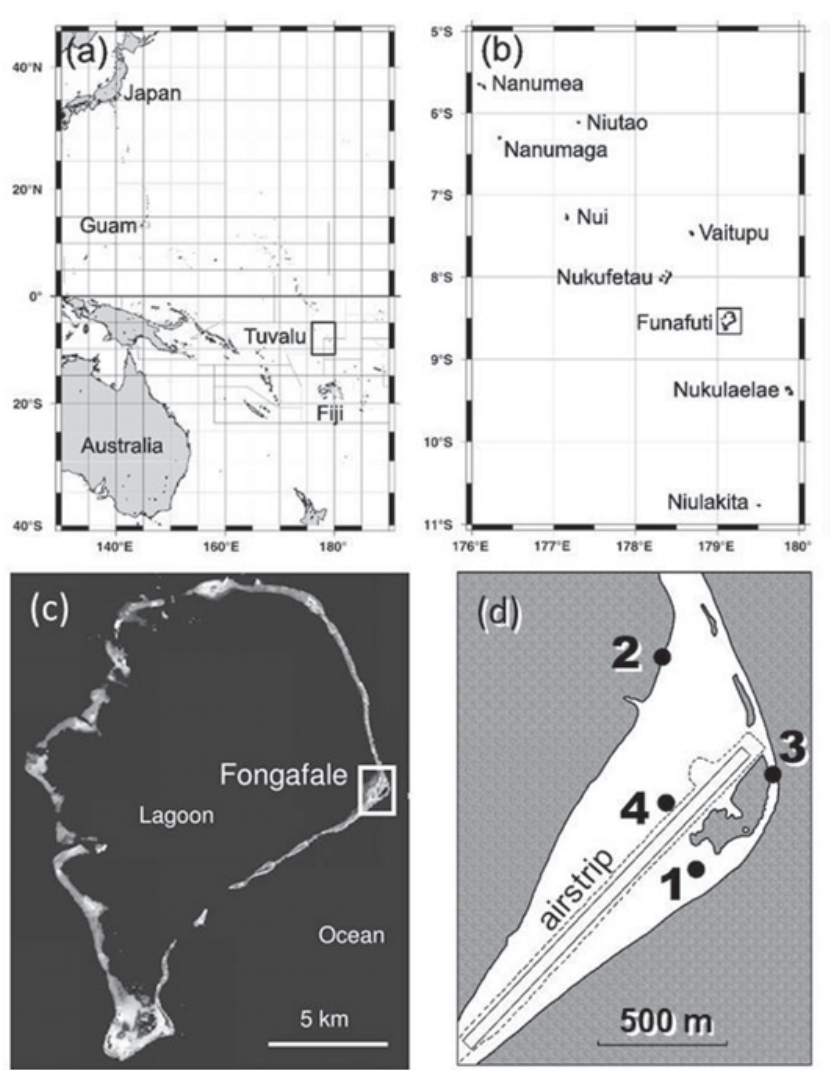

Fig. 1. Map of sampling sites. (a) Tuvalu and adjacent countries in the Pacific; (b) Tuvalu; (c) aerial photograph of Funafuti Atoll; (d) locations of sampling sites on Fongafale Island.

tower (Site 1), 13.iii.2009, sweep net, K. Satake (NIES No. 1305, slide mounted with Canada balsam). Paratypes: 2 males, as holotype (NIES No. 1306-1307).

Diagnostic characteristics: The imago is distinguished by having no virga, complicated inferior volsellae on gonocoxites, weakly dentated megasetae, moderately developed anal point with concave margins, bare wing membranes, weakly developed anal lobe, strongly sinuous $\mathrm{Cu}_{1}$, setaebearing supraalar area and relatively long terminal palpomere.

\section{MALE ( $n=3$, except when otherwise stated)}

Total length $(\mathrm{mm}): 1.80-2.02,1.93$. Wing length $(\mathrm{mm}): \quad 0.84-0.94,0.89$. Total length/wing length:
2.05-2.33, 2.18. Wing length/length of profemur: 2.10-2.23, 2.16. Coloration entirely dark brown, scutellum slightly paler.

\section{Head}

Antenna brown, 13 flagellomeres; flagellar whorl brown, normally developed; groove beginning about flagellomere 3 or 4 ; no apical strong seta. AR $0.51-0.56$, 0.53 . Eye bare, without dorsomedial elongation. Inner verticals 3 (2); outer verticals 5; no postorbitals. Clypeus with 16-18, 17 setae. Tentorium 101-117, $108 \mu \mathrm{m}$ long; 15-17, $16 \mu \mathrm{m}$ wide. Stipes 112-116, $114 \mu \mathrm{m}$ long. Palpomere lengths $(\mu \mathrm{m}): 20-22,21$ (2); 28-31, 30 (2); 46-49, 48 (2); 55 (1); 102-107, 105 (2); palpomeres 2 and 3 seem to be fused. Length ratio of palpomeres $5 / 3$ 2.08-2.33, 2.21 (2). A few sensilla clavata on palpomere 3, straight, like short sensilla chaetica.

\section{Thorax}

Antepronotum without setae. Dorsocentrals normal, uniserial, arising from small pale pits, 10-11, 10; acrostichals start some distance from antepronotum, short and scalpellate, 8-9, 8; prealars 3-4, 3; supraalars $1-2,1$. Scutellum with 5-6, 6 (2) setae in single transverse row.

\section{Wing}

VR 1.44-1.47, 1.46. Wing membrane quite bare. Anal lobe moderately developed but not protruding. Costal extension 105-112, $108 \mu \mathrm{m}$ long. $\mathrm{R}$ with 3-6, 4 setae, other veins bare, except for marginal setae of costa. $\mathrm{Cu}_{1}$ strongly sinuous. Squama bare.

\section{Legs}

Small pulvilli present. Spur of front tibia 30-33, $32 \mu \mathrm{m}$ (2) long; spurs of middle tibia $17 \mu \mathrm{m}$ (2) and 13-15, $14 \mu \mathrm{m}$ (2) long; spurs of hind tibia 33-36, $35 \mu \mathrm{m}$ (2) and $12-15,14 \mu \mathrm{m}$ (2) long. Comb of 8 setae, 17-33 $\mu \mathrm{m}$ long. Pseudospurs lacking. Lengths $(\mu \mathrm{m})$ and proportions of legs:

\begin{tabular}{|c|c|c|c|c|c|c|c|}
\hline & fe & ti & $\mathrm{ta}_{1}$ & $\mathrm{ta}_{2}$ & $\mathrm{ta}_{3}$ & $\mathrm{ta}_{4}$ & $\mathrm{ta}_{5}$ \\
\hline$\overline{p_{1}}$ & $395-436,410$ & $436-467,447$ & $298-316,304$ & $158-182,167$ & $117-129,122$ & $72-75,73$ & $55-63,59$ \\
\hline $\mathrm{p}_{2}$ & $392-474,427$ & $396-422,405$ & $212-236,224$ & $89-104,96$ & $69-72,71$ & $45-47,46$ & $46-52,50$ \\
\hline $\mathrm{p}_{3}$ & $435-499,462$ & $465-502,478$ & $293-315,305$ & $135-138,136$ & $128-133,130$ & $41-68,64$ & $59-61,60$ \\
\hline & \multicolumn{2}{|c|}{ LR } & \multicolumn{2}{|l|}{$\mathrm{BV}$} & SV & \multicolumn{2}{|r|}{$\mathrm{BR}$} \\
\hline$\overline{p_{1}}$ & \multicolumn{2}{|c|}{$0.68-0.69,0.68$} & \multicolumn{2}{|c|}{$2.73-2.81,2.76$} & $2.80-2.86,2$ & \multicolumn{2}{|r|}{$1.8-2.7,2.4$} \\
\hline $\mathrm{p}_{2}$ & \multicolumn{2}{|c|}{$0.53-0.56,0.55$} & \multicolumn{2}{|c|}{$3.95-4.15,4.03$} & $3.53-3.83,3$. & \multicolumn{2}{|r|}{$1.6-2.3,1.9$} \\
\hline $\mathrm{p}_{3}$ & \multicolumn{2}{|c|}{$0.61-0.67,0.64$} & \multicolumn{2}{|c|}{$3.07-3.39,3.19$} & $2.91-3.26,3$. & & $2.5-3.8,3.3$ \\
\hline
\end{tabular}




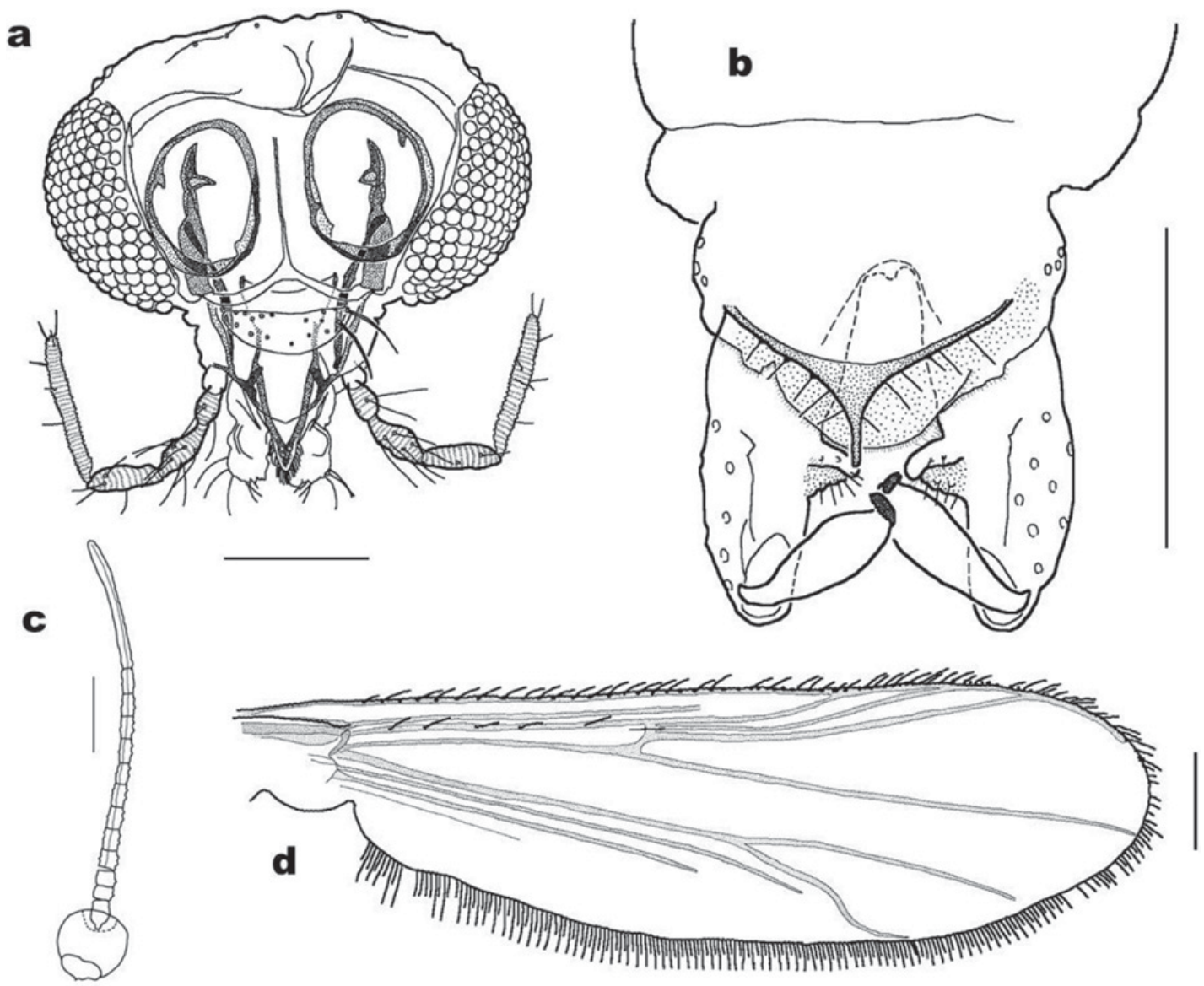

Fig. 2. Compterosmittia longipalpis sp. n. Male. (a) Head; (b) hypopygium; (c) antenna; (d) wing. Scale bar =0.1 mm.

\section{Hypopygium}

Anal point 24.2-31.0, $26.9 \mu \mathrm{m}$ long, 28.2-40.8, $34.5 \mu \mathrm{m}$ (2) wide at base; with 6-7 strong lateral setae along concave lateral margins, void of microtrichiae at tip; laterosternite IX with 3-5, 4 setae. Phallapodeme 40-44, $42 \mu \mathrm{m}$ (2) long; transverse sternapodeme nearly straight, with rounded oral projections, 41-49, $45 \mu \mathrm{m}$ (2) long. Virga absent. Gonocoxite 112-124, $120 \mu \mathrm{m}$ long, with partially broad inferior volsella with dorsal rounded projection free of microtrichia and ventral lobe covered with microtrichiae. Gonostylus 53-58, $55 \mu \mathrm{m}$ (2) long, with semicircular, 6- $\mu \mathrm{m}-$ long, vestigially dentate megaseta. HR 1.93-2.37, 2.15 (2); HV 3.37-3.85, $3.61(2)$.

\section{Remarks}

C. longipalpis apparently keys to Compterosmittia dentispina Sæther, 1981 in the review of the genus Compterosmittia Sæther, 1981 by Mendes et al. (2004) and Lin et al. (2013), because it has no protruding of the anal lobe of wing, 13-segmented flagellomeres of antenna, no virga, the complicated inferior volsella and the dentate megaseta. However, $C$. longipalpis can be separated from $C$. dentispina by the darker thorax, quite bare wing, weak but conspicuous anal lobes, vestigial dentation of megaseta and the larger length ratio of palpomere $5 / 3(2.21)$. The male of $C$. dentispina has pale brown thorax, the wing with 2-4 setae on membrane, the reduced anal lobe and the strong dentation of megaseta (Sæther, 1981). With the palpomere lengths presented by Sæther (1981), a calculation of the length ratio of palpomere $5 / 3$ of C. dentispina is 1.12 .

\section{Pseudosmittia tuvaluensis sp. n. (Fig. 3)}

Type material: Holotype male, TUVALU: Funafuti Atoll, Fongafale Island, swamp in a mangrove forest (Site 3), 11.iii.2009, sweep net, K. Satake (NIES No. 1301, slide mounted with Canada balsam). Paratypes: seven males, as holotype (NIES No. 1302-1303, D0466-D0469). Direct sequencing identified three haplotypes of $C O I$ gene from four specimens. The three haplotypes differed from each other by two nucleotides at three sites. The accession numbers were AB769378 to AB769380.

Diagnostic characteristics: The male imago is distinguished from other congeners with completely bare eyes, forked postcubitus veins, a broadly triangular 

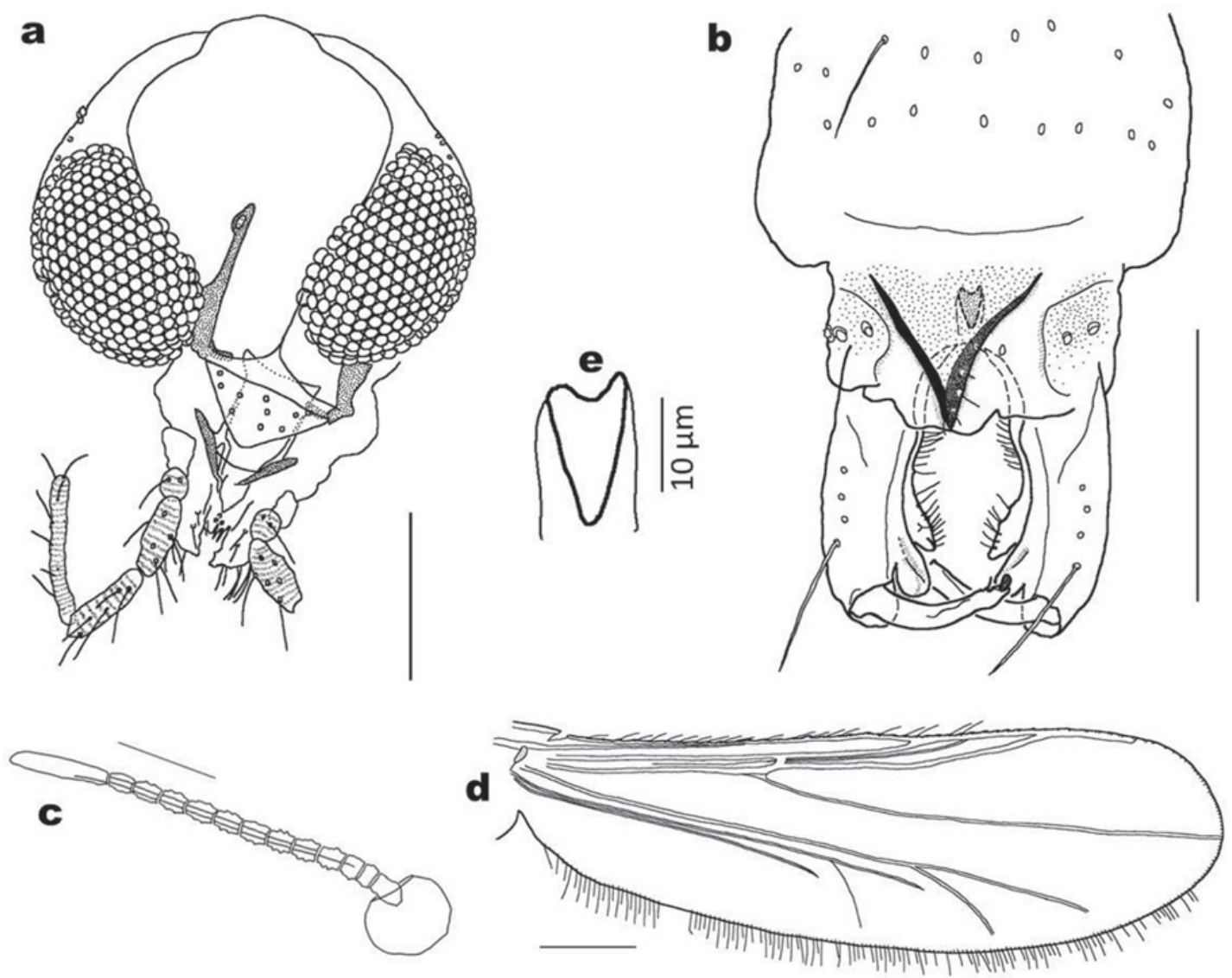

Fig. 3. Pseudosmittia tuvaluensis sp. n. Male. (a) Head; (b) hypopygium; (c) antenna; (d) wing; (e) virga. Scale bar =0.1 mm, except for virga.

anal point with straight side margins and sharply pointed apex, a broad and short virga, inferior volsellae on gonocoxites with accessory lobes situated posterior to inferior volsella, minute square cristae dorsalis, ultimate flagellomere without apical seta, and a very low AR.

\section{MALE ( $n=3$, except when otherwise stated)}

Total length (mm) 1.48-1.79, 1.65. Wing length (mm) $0.71-0.80,0.74$. Total length/wing length $2.08-2.52,2.24$. Wing length/length of profemur 2.32-2.35, 2.33 (2). Coloration blackish brown.

\section{Head}

Antenna brown, 13 flagellomeres; flagellar whorl brown, normally developed; groove beginning about flagellomere 3 or 4; no apical strong seta. AR 0.31 (3). Eye bare, without dorsomedian elongation. Inner verticals 4-5, 5; outer verticals 4-5, 4; no postorbitals. Clypeus with 10-11, 10 setae. Tentorium 97-103, $100 \mu \mathrm{m}$ long; $16-18,16 \mu \mathrm{m}$ wide. Palpomere lengths $(\mu \mathrm{m}): 22 ; 20-27,24$; 50-57, 52; 61-64, 63; and 92-97, 94. Palpomere 3 with a few indistinct sensilla clavata; palpomere 4 without sensilla clavata.

\section{Thorax}

Antepronotum with 3-4, 4 setae. Dorsocentrals normal, uni- to bisereal, arising from small pale pits, 17-20, 19; acrostichals arising at paler area in the center of scutum, 2; prealars 4-54, no supraalars. Scutellum with 6 setae in single transverse row.

\section{Wing}

VR 1.73-1.93, 1.80. VR2 1.50 (1). Costal extension 18 $76,38 \mu \mathrm{m}$ long. All veins bare, except for marginal setae of costa; costal extension with sparse marginal setae. Squama bare. Postcubitus vein forked.

\section{Legs}

Pulvilli absent. Spur of front tibia $32 \mu \mathrm{m}$ long, spurs of middle tibia 17-20, $19 \mu \mathrm{m}$ long, spurs of hind tibia 41-44, $43 \mu \mathrm{m}$ and $15 \mu \mathrm{m}$ long. Comb of 13 setae $23-41 \mu \mathrm{m}$ long. Lengths $(\mu \mathrm{m})$ and proportions of legs: 


\begin{tabular}{|c|c|c|c|c|c|c|c|}
\hline \multicolumn{2}{|r|}{ fe } & ti & $\mathrm{ta}_{1}$ & $\mathrm{ta}_{2}$ & $\mathrm{ta}_{3}$ & $\mathrm{ta}_{4}$ & $\mathrm{ta}_{5}$ \\
\hline$\overline{p_{1}}$ & $302-345,320$ & $339-353,346$ & $167-178,174$ & $71-79,76$ & $61-62,61$ & $41-44,43$ & $46-51,48$ \\
\hline $\mathrm{p}_{2}$ & $341-350,346$ & $342-368,357$ & $172-178,176$ & $79-86,84$ & $60-69,65$ & $37-48,44$ & $40-48,46$ \\
\hline $\mathrm{p}_{3}$ & $314-340,331$ & $346-371,361$ & $190-218,208$ & $96-104,101$ & $103-108,105$ & $43-50,47$ & $44-47,46$ \\
\hline & \multicolumn{2}{|c|}{ LR } & \multicolumn{2}{|l|}{$\mathrm{BV}$} & SV & \multicolumn{2}{|c|}{$\overline{\mathrm{BR}}$} \\
\hline$\overline{p_{1}}$ & \multicolumn{2}{|c|}{$0.49-0.52,0.50$} & \multicolumn{2}{|c|}{$3.69-3.72,3.68$} & $3.70-3.93,3$ & & $2.0-2.4,2.2$ \\
\hline $\mathrm{p}_{2}$ & \multicolumn{2}{|c|}{$0.48-0.50,0.49$} & \multicolumn{2}{|c|}{$3.52-3.96,3.71$} & $3.97-4.04,3$ & & $2.0-2.4,2.2$ \\
\hline $\mathrm{p}_{3}$ & \multicolumn{2}{|c|}{$0.55-0.59,0.58$} & \multicolumn{2}{|c|}{$2.97-3.03,3.01$} & $3.26-3.47,3$ & & $1.9-2.8,2.3$ \\
\hline
\end{tabular}

\section{Hypopygium}

Anal point 54-60, $58 \mu \mathrm{m}$ long. Laterosternite IX with 3 setae. Phallapodeme 48-55, $53 \mu \mathrm{m}$ long; transverse sternapodeme 59-75, $64 \mu \mathrm{m}$ long, straight, without oral projections. Virga broad, triangular, 15-19, $17 \mu \mathrm{m}$ long. Gonocoxite 111-136, $120 \mu \mathrm{m}$ long, with large bifurcate inferior volsella. Gonostylus 57-60, $58 \mu \mathrm{m}$ long; with minute preapical crista dorsalis; with 6-8, $7 \mu \mathrm{m}$ long megaseta. HR 1.88-2.35, 2.06; HV 2.59-3.01, 2.84.

\section{Remarks}

Combination of no strong seta on antennal apex, the broadly triangular anal point, the forked postcubitus, the low AR (about 0.3), the simple virga and the duplicate inferior volsella separate $P$. tuvaluensis from other congeners except for an Oceanian species Pseudosmittia dupla (Tokunaga, 1964). However, P. tuvaluensis can be separated from $P$. dupla by the posteriorly situated accessory lobe of inferior volsella and the small but apparent crista dorsalis on the gonostylus. $P$. dupla has an accessory lobe just covered by an inferior volsella and no crista dorsalis on a gonostylus (Tokunaga, 1964; Ferrington and Sæther, 2011).

\section{Pseudosmittia amplexivirga sp. n. (Fig. 4)}

Material examined: 1 male, TUVALU: Funafuti Atoll, Fongafale Island, a swamp in a mangrove forest (Site 3), 11.iii.2009, sweep net, K. Satake (NIES No. 1304, slide mounted with Canada balsam).

Diagnostic characteristics: The male imago is distinguished from other congeners with completely bare eyes, forked postcubitus veins, a broadly triangular anal point with straight side margins and a sharply pointed apex, a slender virga with lateral lamellae, a large triangular inferior volsella on a gonocoxite and a preapical crista dorsalis on a gonostylus.

\section{MALE IMAGO $(n=1)$}

Total length $1.93 \mathrm{~mm}$. Wing length $0.86 \mathrm{~mm}$. Total length/wing length 2.26. Coloration entirely dark brown.

\section{Head}

Antenna brown, 13 flagellomeres; flagellar whorl brown, normally developed; groove beginning at flagellomere 3; no apical strong seta. AR 0.70. Eye bare, without dorsomedian elongation. Inner verticals 3; outer verticals 2; no postorbitals. Clypeus with 13 setae. Tentorium $95 \mu \mathrm{m}$ long, $20 \mu \mathrm{m}$ wide. Stipes $80 \mu \mathrm{m}$ long. Apex of palpomere 4, with a somewhat thicker apical spine, extend ventrally. Palpomere lengths ( $\mu \mathrm{m}): 23,23,49,104,101$; palpomeres 2 and 3 seem to be fused. Palpomere 3 with a few indistinct sensilla clavata; palpomere 4 without sensilla clavata.

\section{Thorax}

Antepronotum without setae. Dorsocentrals normal, unisereal, arising from small pale pits, 15; acrostichals 2, arising at the center of scutum; prealars 3; no supraalars. Scutellum with 3 setae in single transverse row. Postcubitus veins forked.

\section{Wing}

VR 1.65, VR2 1.43. Wing membrane quite bare. Anal lobe moderately developed. Costa not produced. All veins bare, except for marginal setae of costa. Squama bare.

\section{Legs}

Pulvilli absent. Spur of front tibia $32 \mu \mathrm{m}$ long, of middle tibia $27 \mu \mathrm{m}$ long, spurs of hind tibia $38 \mu \mathrm{m}$ and 25 $\mu \mathrm{m}$ long. Comb of 11 setae, $21-30 \mu \mathrm{m}$ long. Lengths $(\mu \mathrm{m})$ and proportions of legs:

\begin{tabular}{lccccccc}
\hline & $\mathrm{fe}$ & $\mathrm{ti}$ & $\mathrm{ta}_{1}$ & $\mathrm{ta}_{2}$ & $\mathrm{ta}_{3}$ & $\mathrm{ta}_{4}$ & $\mathrm{ta}_{5}$ \\
\hline $\mathrm{p}_{1}$ & 380 & 400 & 237 & 122 & 96 & 61 & 50 \\
$\mathrm{p}_{2}$ & 424 & 429 & 234 & 119 & 83 & 56 & 55 \\
$\mathrm{p}_{3}$ & 393 & 425 & 249 & 147 & 141 & 66 & 53 \\
\hline & & $\mathrm{LR}$ & $\mathrm{BV}$ & $\mathrm{SV}$ & & $\mathrm{BR}$ \\
\hline $\mathrm{p}_{1}$ & & 0.59 & 3.09 & 3.28 & & 3.4 \\
$\mathrm{p}_{2}$ & & 0.54 & 3.48 & 3.65 & & 3.3 \\
$\mathrm{p}_{3}$ & & 0.58 & 2.62 & 3.29 & & 4.4 \\
\hline
\end{tabular}

\section{Hypopygium}

Anal point $59 \mu \mathrm{m}$ long. Phallapodeme $56 \mu \mathrm{m}$ long; transverse sternapodeme $61 \mu \mathrm{m}$ long, without oral 

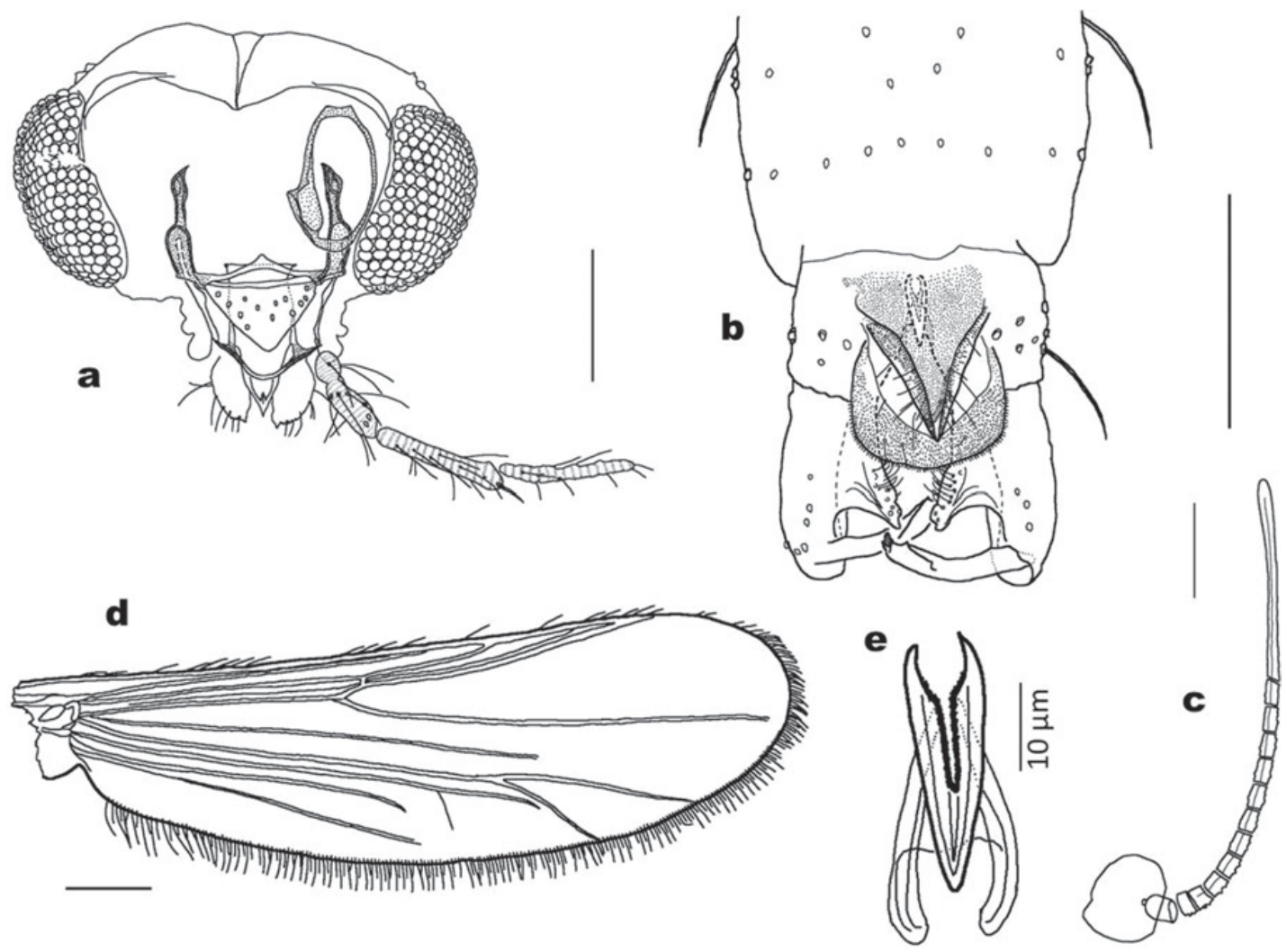

Fig. 4. Pseudosmittia amplexivirga sp. n. Male. (a) Head; (b) hypopygium; (c) antenna; (d) wing; (e) virga. Scale bar = 0.1 mm, except for virga.

projections, arched. Virga $28 \mu \mathrm{m}$ long, with a pair of lateral lamellae. Gonocoxite $112 \mu \mathrm{m}$ long, with large triangular inferior volsella. Gonostylus $81 \mu \mathrm{m}$ long; with minute square preapical crista dorsalis; with $7 \mu \mathrm{m}$ long megaseta. HR 1.84; HV 2.36.

\section{Remarks}

Combination of no strong seta on antennal apex, the broadly triangular anal point, the lamellate virga, the protruding triangular inferior volsella and the forked postcubitus may separate this species from other congeners. Apart from structure of virga, above mentioned characters are shared by Pseudosmittia kraussi (Tokunaga, 1964), Pseudosmittia palauensis (Tokunaga, 1964) and Pseudosmittia triangula (Tokunaga, 1964), which have stout and simple virga and have distribution within Oceanian region (Tokunaga, 1964; Ferrington and Sæther, 2011). According to Ferrington and Sæther (2011), lamellar structures flanking virga are known among three species belonging to the brevifurcata-group, namely, Pseudosmittia lamellata Andersen et al., 2010, Pseudosmittia propetropis Ferrington and Sæther, 2011 and Pseudosmittia tropis Andersen et al., 2010 recorded from Afrotropical and Neotropical regions. However, all of them quite differ from $P$. amplexivirga by having the unbranched postcubitus, the narrow and blunt anal point and the weak inferior volsella appressed to the gonocoxite.

\section{Chironomus sp. Tuvalu (Fig. 5)}

Material examined: 4 larvae, TUVALU: Funafuti Atoll, Fongafale Island, a puddle in a taro swamp, 11.iii.2009, D-frame net sweeping, K. Satake (NIES No. 1312-1314, D0481). Twenty-seven 4th instar larvae and two 3rd instar larvae of probably the same species as slide specimens, stored in $99.5 \%$ ethyl alcohol. The partial $C O I$ gene sequence from one specimen was obtained (accession number AB769382).

\section{Larva, 4th instar $(n=3)$}

Head capsule yellow, with dark mentum. Antenna segment lengths $(\mu \mathrm{m})$ : $54-60 ; 16-17 ; 3-4 ; 4-5 ; 3$; blade 68-78; subsidiary 4-5 $\mu \mathrm{m}$; style 7-8. AR 1.9-2.2. Lauterborn organs $4-5 \mu \mathrm{m}$. Ring organ basal. Very strong (but pale) seta on 1st antennal segment, 18-21 $\mu \mathrm{m}$ long, arising from mid-segment and extending to near apex of segment 1. Mentum width 110-113 $\mu \mathrm{m}$, dorsal surface smooth. Mandible 120-132 $\mu \mathrm{m}$. Premandible $200 \mu \mathrm{m}$, apical tooth blunt, brush normally developed.

Labrum narrowed and tapering anteriorly. SI plumose, SII simple. Labral lamellae normally developed. Pecten epipharyngis composed of a combed plate with about 15 teeth. Premandible with two apical teeth. Mentum with a trifid median tooth, and six lateral teeth in each side, second lateral tooth appressed to first lateral tooth making 

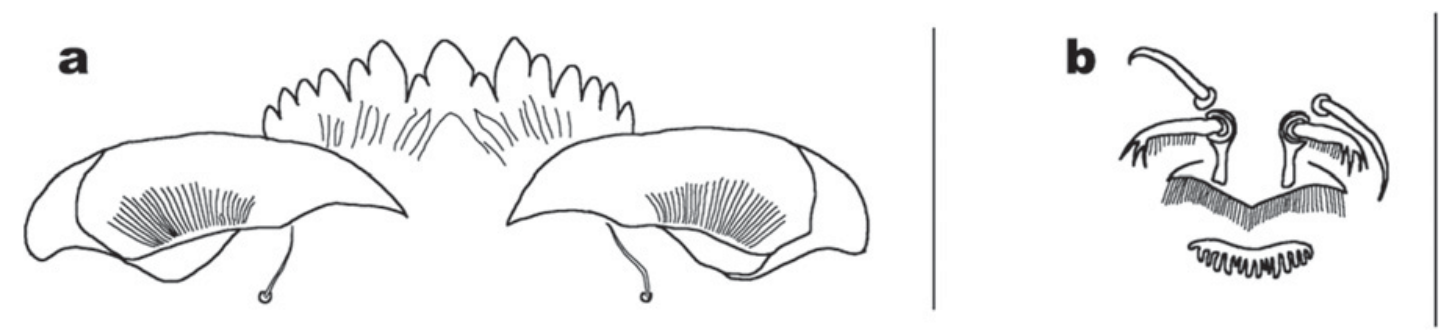

Fig. 5. Chironomus sp. Tuvalu. Larva. (a) Mentum; (b) labium. Scale bar $=0.1 \mathrm{~mm}$.

the notch between them shallow, second and third teeth divided by a deep notch, third to six lateral teeth gradually shorten, fourth lateral tooth slightly shorter than the trend.

Abdomen $(n=1)$. Anterior parapods crowned with simple dark yellow claws. Procercus not pigmented, 6 apical setae $325 \mu \mathrm{m}$ long. Posterior parapod claws large, curved, simple, dark yellow. Seventh abdominal segment with a pair of caudolateral processes. Eighth abdominal segment with two pairs of long blood gills.

\section{Remarks}

This larva belongs to medium-sized species among the genus Chironomus Meigen, 1803. Morphology of this larva is typical of the genus, with a pair of lateral tubules and two pairs of ventral tubules. The partial COI sequences will be helpful for confirmation to associate with adult specimens in future. The habitat of this species is a shallow freshwater puddle in a taro swamp.

\section{General characteristics of the Tuvaluan chironomid fauna}

In this study, four species belonging to three genera of chironomids were found in Tuvalu. The previously known habitats of Compterosmittia have been phytotelmata (Cranston and Kitching, 1995); therefore, axils of Pandanus, for example, seemed to be a candidate habitat in Tuvalu, although such habitats have not yet been examined. The habitats of Pseudosmittia are uncertain in many cases. At least two Pseudosmittia species are aquatic, but many species are said to be terrestrial or semiterrestrial (Cranston et al., 1989). As larvae of Chironomus sp. Tuvalu were found only in a taro field, the habitat of this species is apparently fresh water. Thus, at least Chironomus sp. Tuvalu and probably C. longipalpis depend on inland freshwater environments in Tuvalu.

Each genus found in Tuvalu has widespread distribution among oceanic islands. Compterosmittia have been recorded from Micronesia (Tokunaga, 1964) and Lesser Antilles (Sæther, 1981). Each species of this genus is endemic to a certain island group or an archipelago. Pseudosmittia have been recorded from the same distribution as Compterosmittia (Tokunaga, 1964; Sæther, 1981), plus in Samoa (Edwards, 1928), Greater Antilles (Sublette and Wirth, 1972), the Seychelles (Sæther, 2004) and Macaronesia (Murray et al., 2004). Several species of this genus are endemic to certain island groups, whereas several species are widespread (for example Pseudosmittia brachydicrana, recorded from Micronesia, Hawaii, Jamaica and several other tropical islands; Andersen et al., 2010; Ferrington and Sæther, 2011). Chironomus have been recorded from the same distribution as Pseudosmittia (Edwards, 1928; Tokunaga, 1964; Spies and Reiss, 1996; Murray et al., 2004; Sæther, 2004), plus in the Marquesas (Edwards, 1933). Thus, at the generic level, the chironomids found in Tuvalu are very common among oceanic islands, whereas at the specific level they are proper to Tuvalu. The Tanypodinae, Cricotopus and Tanytarsus, common members of island chironomid faunae, have not yet been collected in Tuvalu.

Acknowledgements. We are grateful to Dr. K. Takamura for the fruitful discussion and to Dr. H. Kayanne and Dr. P. D. Nunn for advice and support during the study. We also thank Dr. Y. Umezawa, Dr. S. Nakada and Mr. Emilio for their help in the field; Dr. N. Kondo, Dr. K. Ohbayashi and Ms. Y. Oikawa for analyses of the COI gene sequences; and Ms. M. Furusawa and Ms. K. Kato for their technical and secretarial support. This research was partially supported by JSPS KAKENHI Grant Number 24241078, Environment Research and Technology Development Fund, Ministry of the Environment, Japan (No. Ba-085), and JST/JICA SATREPS (Science and Technology Research Partnership for Sustainable Development). This study is a contribution to the Biodiversity Priority Program of the National Institute for Environmental Studies. Sampling of chironomids was performed under an agreement between Japan and Tuvalu. We also thank two anonymous referees for helpful comments that improved earlier versions of this paper.

\section{References}

Andersen T., Sæther O.A. and Mendes H.F., 2010. Neotropical Allocladius Kieffer, 1913 and Pseudosmittia Edwards, 1932 (Diptera: Chironomidae). Zootaxa, 2472, 1-77.

Cranston P. and Kitching R., 1995. The Chironomidae of Austro-oriental phytotelmata (plant-held waters): Richea pandanifolia Hook. f. In: Cranston P.S. (ed.), Chironomids: From Genes to Ecosystems, CSIRO Publications, East Melbourne, Australia, 225-231.

Cranston P.S., Oliver D.R. and Sæther O.A., 1989. The adult males of Orthocladiinae (Diptera: Chironomidae) of the 
Holarctic region. Keys and diagnoses. Entomol. Scand. Suppl., 34, 165-352.

Edwards F.W., 1928. Nematocera. Insects Samoa, 6, 23-102.

Edwards F.W., 1933. Mycetophilidae, Culicidae, and Chironomidae and additional records of Simuliidae, from the Marquesas Islands. Bull. Bernice P. Bishop Mus., 114, 85-92.

Ferrington L.C., Jr. and Sæther O.A., 2011. A revision of the genera Pseudosmittia Edwards, 1932, Allocladius Kieffer, 1913, and Hydrosmittia gen. n. (Diptera: Chironomidae, Orthocladiinae). Zootaxa, 2849, 1-314.

Hardy D.E., 1960. Diptera: Nematocera-Brachycera. Insects Hawaii, 10, xii + 368 p.

Laird M., 1956. Studies of the mosquitoes and freshwater ecology in the south Pacific. R. Soc. N. Z. Bull., 6, 1-212.

Lin X., Yao Y., Liu W. and Wang X., 2013. A review of the genus Compterosmittia Sæther, 1981 (Diptera: Chironomidae) from China. Zootaxa, 3669, 129-138.

Mendes H.F., Andersen T. and Sæther O.A., 2004. A review of Antillocladius Sæther, 1981; Compterosmittia Sæther, 1981 and Litocladius new genus (Chironomidae, Orthocladiinae). Zootaxa, 594, 1-82.

Murray D.A., Hughes S.J., Furse M.T. and Murray W.A., 2004. New records of Chironomidae (Diptera: Insecta) from the Azores, Macaronesia. Ann. Limnol. - Int. J. Lim., 40, 33-42.
Pinder L.C.V., 1989. The adult males of Chironomidae (Diptera) of the Holarctic region. Introduction. Entomol. Scand. Suppl., 34, 5-9.

Sæther O.A., 1980. Glossary of chironomid morphology terminology (Diptera: Chironomidae). Entomol. Scand. Suppl., 14, 1-51.

Sæther O.A., 1981. Orthocladiinae (Diptera: Chironomidae) from the British West Indies, with descriptions of Antillocladius n.gen., Lipurometriocnemus n.gen., Compterosmittia n.gen. and Diplosmittia n.gen. Entomol. Scand. Suppl., 16, 1-46.

Sæther O.A., 2004. The Chironomidae of the Seychelles. Ann. Limnol. - Int. J. Lim., 40, 285-308.

Spies M. and Reiss F., 1996. Catalog and bibliography of Neotropical and Mexican Chironomidae. Spixiana Suppl., 22, 61-119.

Sublette J.E. and Wirth W.W., 1972. New genera and species of West Indian Chironomidae (Diptera). Fla. Entomol., 55, 1-17.

Tokunaga M., 1964. Insects of Micronesia. Diptera: Chironomidae. Insects Micronesia, 12, 485-628.

Yamano H., Kayanne H., Yamaguchi T., Kuwahara Y., Yokoki H., Shimazaki H. and Chikamori M., 2007. Atoll island vulnerability to flooding and inundation revealed by historical reconstruction: Fongafale Islet, Funafuti Atoll, Tuvalu. Global Planet. Change, 57, 407-416. 